\title{
La actividad situada y/o el conocimiento socialmente distribuido
}

\section{Carlos Lozares}

Universitat Autònoma de Barcelona. Departament de Sociologia

08193 Bellaterra (Barcelona). Spain

Miembro del QUIT

\section{Resumen}

La controversia entre, de un lado, la aproximación pragmática, situacional y contextual de la acción (o actividad) y del lenguaje y, de otro, la normativa, atributiva y/o descontextualizada tiene una larga historia en las ciencias sociales. Esta controversia se ha actualizado y ha adquirido mayor extensión y profundidad a partir de la aparición de las ciencias de la comunicación, computación, inteligencia artificial, etc. y con la emergencia de los fenómenos vinculados a la presencia de nuevos artefactos informativos, automatizados y/o inteligentes. Estos instrumentos están modificando la relación e interacción práctica y cognitiva de los individuos con dichos instrumentos y de los mismos individuos entre sí. La terminología asociada a esta controversia tiene diversas denominaciones: acción/actividad situada v. sistemas simbólicos, (actividad descontextualizada); conocimiento socialmente distribuido v. conocimiento atributivo e individualizado; nueva inteligencia artificial v. inteligencia artificial clásica, (sistemas expertos) ${ }^{1}$.

Palabras clave: conocimiento cotidiano, actividad situada, conocimiento social distribuido, sistema experto, inteligencia artificial, interacción social.

\section{Abstract. The situated activity andlor the knowledge distributed socially}

There is a very important, historical controversy in the social sciences between, on the one hand, a pragmmatically, contextualized approach to action or activity, and, on the other, a normative, uncontextualized approach. This controversy is current because of the increasing importance of the sciences of communication, computation, artificial intelligence and so on, as well as the presence of automated, intelligent instruments. These devices have changed the relationships and interaction between instruments and individuals and also between individuals. Terminology associated with these divergent

1. Agradezco a Aaron Cicourel, profesor de la Faculty of Cognitive Sciences de la UCSD, al profesor Fausto Miguélez del Departament de Sociologia de la UAB, a la profesora Marta Sadurny del Departament de Psicologia de la Universitat de Girona, a la profesora Anna Estany del Departament de Filosofia de la UAB, las sugerencias y críticas que me han hecho en la elaboración de este artículo. Con todo, la responsabilidad de lo escrito queda de mi única incumbencia. Este artículo es uno de los resultados de mi estancia en la Universidad de California, San Diego, en el verano de 1998, hecha posible por una beca de la Generalitat de Catalunya. 
approachs has entered many fields: Situated Activity (Action) v. Simbolic System, (Uncontextualized Activity); Social Distributed Knowledge v. Attributed, Individualized Knowledge, New Artificial Intelligence v. Classical Artificial Intelligence (Expert System).

Key words: Everyday Knwoledge, Situated Actvity, Social Distributed Knwoledge, Expert System, Artificial Intelligence, Social Interaction.

\section{Sumario}

I Parte. Elementos de identificación

1. La actividad situada y/o conocimiento socialmente distribuido

2. El contexto en la perspectiva de AS y/o CSD

II Parte. Bases teóricas y metodológicas y orientaciones para la investigación en la AS/CSD

1. Una panoplia más o menos convergente de teorías que provienen de diversas disciplinas

2. Orientaciones metodológicas generales en las investigaciones sobre la AS/CSD
3. Pautas y esquemas de referencia observacional y analítico-interpretativos y algunas orientaciones técnicoobservacionales

III Parte. Insuficiencias de (y aportaciones a) la teoría de la AS/CSD La acción y la actividad sociales La actividad situada, situación, contexto y el control/poder

La interacción social

Observaciones finales

Bibliografía

\section{PARTE ELEMENTOS DE IDENTIFICACIÓN}

\section{La actividad situada y/o conocimiento socialmente distribuido}

\subsection{El estado de la cuestión y de la controversia}

La aparición, extensión e implantación de la informática, la robótica, los sistemas inteligentes y otros artefactos en el trabajo y en otras muchas esferas de la actividad humana tienen un rol decisivo en las relaciones entre los agentes y las máquinas, entre los mismos agentes y, extensivamente, entre la tecnología, la cognición y la actividad humana. Los artefactos son muy variados y van desde los sistemas notacionales y vocabularios especiales hasta las máquinas más automatizadas. Todos ellos presentan tanto una cara estructural como otra más procesual; una forma representacional-cognitiva frente a otra más fáctica y material. Son los agentes sociales quienes los inventan o adquieren, distribuyen, usan, interfieren con ellos y los desgastan. Pero, sobre todo, al «relacionarse» estos artefactos entre sí y con los agentes condicionan o facilitan la interacción entre los propios agentes, sea como instrumentos de 
apoyo o colaboración, sea como potenciación de las capacidades de los sujetos sociales. Las connotaciones cognitivas de estas interacciones y actividades son evidentes (Engeström y Middleton, 1996).

Los modelos de conocimiento disponibles en cada una de las disciplinas mencionadas tomadas aisladamente tienen limitaciones para abordar muchos de los problemas y fenómenos surgidos por la aparición de (e interacción con) dichos artefactos. Es decir, que se requieren nuevas reflexiones conceptuales, nuevos métodos y modelos en la dirección de una mayor convergencia disciplinaria (Conein, 1994). Por ejemplo, la psicología y la sociología del trabajo tienen intereses y exigencias metodológicas comunes en el estudio de las técnicas de asistencia al trabajo descentralizado y distribuido. Para que la necesaria convergencia entre disciplinas tenga éxito en este terreno parece necesario que la perspectiva del análisis no ha de provenir ni exclusivamente de la lógica, condicionamientos y representación de los artefactos y/o de sus exigencias tecnológicas, ni tampoco de la sola capacidad cognitiva y práctica de los agentes, ni de una aislada contextualización situacional, sino sobre todo de la interacción de actividades y representaciones cognitivas mutuas de los agentes con los instrumentos y de los agentes entre sí (Heath y Luff, 1994). De todas maneras, van surgiendo voces e investigaciones que van en esta dirección dentro de lo que se ha dado en llamar «actividad situada» (AS) y/o "conocimiento socialmente distribuido» (CSD) con orientación interdisciplinaria y que trata de estudiar los fenómenos en las condiciones mismas de su emergencia situacional e interactiva. Esta orientación supone, por ejemplo, para Cicourel (1994) la necesaria toma en cuenta de la interacción, producción, modificación, distribución de (y entre) la acción, los componentes sociocognitivos y los contextos sociales en la interferencia que se da entre artefactos y sujetos; la tendencia ha tendido a contemplar unilateralmente estos fenómenos a partir de un conocimiento preprogramado y determinado sobre una actividad aislada del contexto y con los sujetos sociales como únicos soportes de los contendios cognitivos (Conein, 1994; Suchman, 1993).

Esta nueva perspectiva surge cara a (o contra) la denominada simbólico/formal de la inteligencia artificial clásica (IA). Para esta versión son las estructuras y los procesos simbólicos los que predeterminan la actividad humana. Por tanto, focaliza su preocupación sobre dichas estructuras y representaciones simbólicas: toda acción tiene en ellas su único referente y antecedente. En este sentido, para entender los procesos de acción que se dan en el mundo social bastaría con comprender los procesos mentales y la naturaleza de las transformaciones inputloutput de los individuos (Norman, 1993). La idea de expertise como noción cognitiva individualizante es capital (Engeström y Middleton, 1996).

La perspectiva de la AS y/o CSD, por el contrario, establece que, para considerar, analizar o interpretar cualquier fenómeno de la práctica y/o cognitivo, es imprescindible considerarlo como una actividad interactvia y en situación (Greno y Moore, 1993). Se centra, por tanto, sobre las estructuras de la realidad, en cómo guían y se condicionan mutuamente el comportamien- 
to y la cognición evitando la diglosia entre conocimiento y mundo, en la actividad de los agentes, de los grupos y de las máquinas en situación y en contexto, en el ajuste y la acomodación de la mente a las situaciones, a las interacciones sociales. No es de extrañar que los partidarios de la IA clásica y los sistemas simbólicos estigmaticen a esta perspectiva con la «terrible» calificación de behavorista (Norman, 1993).

La controversia que nace de estas dos versiones ha estado presente en la sociología, bajo otras coberturas, temáticas y denominaciones; baste recordar lo que se opuso (y supuso) la escuela de Chicago, Blumer y Becker, el interaccionismo, la fenomenología sociológica de Schutz (en realidad el «creador» del conocimiento socialmente distribuido bajo una visión fenomenológica), la etnometodología de Garfinkel y Cicourel y la aproximación de Goffman a (y contra) una sociología en la que brillaban por su ausencia los conceptos de situación, interacción como también la diemensión cogntiva. Con todo, no es posible, desde mi punto de vista, amalgamar hoy a los que se reclaman de la AS o del CSD con cualquier forma de fenomenología sociológica, ni mucho menos con el constructivismo.

En los dos apartados que vienen a continuación separo, de un lado, la actividad o acción situada del conocimiento socialmente distribuido. Aunque esta distinción sea de matiz, me permite profundizar en su contenido. Hecha la distinción serán tratados, en el resto del artículo, como conceptos equivalentes.

\subsection{La actividad situada y su contextualización}

El término acción/actividad situada (AS), está ya presente en los trabajos del interaccionismo, pero, con el contenido que aquí se plantea, se "patenta" por (y se extiende a partir de) Suchman (1983), aunque ella dé al término una connotación más cognitiva siguiendo la idea de la etnometodología, de quien se considera heredera. La acción o actividad situada ha de verse como interacción con los artefactos e instrumentos bajo las circunstancias sociales que los envuelven y no sólo como interacción entre sujetos sociales. Para el análisis situado, los recursos e instrumentos, sobre todo los objetos informativos y automatizados, son también mediadores y actuantes entre el mundo y los agentes: la actividad, los componentes cognitivos de los agentes y artefactos y el contexto son interactuantes. Dentro de esta perspectiva general se pueden enfatizar uno u otro de dos enfoques: 1) uno que se centra más en la interacción, opción que recalca la actividad como intercambio: comunicación verbal, participación, representación y distribución de recursos, etc. 2) otro más centrado en la dimensión cognitiva de la interacción con los artefactos del entorno, indicadores, señales, información, mecánica, etc.; pone el acento sobre la percepción y la distribución cognitiva en la comunicación con el entorno (Conein y Jacopin, 1994). La perspectiva de la AS se reconoce más en los trabajos que van en el segundo enfoque, no obstante las voces de buen sentido común científico que claman por la integración. Cualquier diglosia 
en este aspecto carece de sentido. Las representaciones, los símbolos, los procesos de identificación, como cualquier otro componente cognitivo, se generan y se transforman por la interacción en la actividad de (y entre) máquinas y objetos, recursos y agentes sociales (Engestrom, 1987). Esta preocupación de la AS por integrar todos los factores intervinientes en la situación se encuentra en muchas de las tendencias actuales, sea dentro la inteligencia artificial en William Clancey, de la etnometodología a la que se considera vinculada Lucy Suchman, de la etnografía cognitiva de Jean Lave o desde los agentes autómatas y las arquitecturas reactivas de Rodney Brooks. Desde mi punto de vista, se ha insistir en que la AS, en su connotación actual, se constituye más bien como convergencia, vivero o hervidero de preocupaciones e ideas que como cuerpo doctrinal establecido o como afirmación teórica. Los elementos del contexto en los que más se centra la perspectiva de la AS son el espacio/tiempo y los artefactos ya que tienen un rol nodal en la acción situada. Es arriesgado, en mi opinión, establecer, como hacen Conein y Jacopin (1994), una distinción entre contexto espaciotemporal estático, independiente de la actividad del agente, y el dinámico, que se modifica por su acción. Si es estático no pertenece a la interacción y por tanto no es pertinente a ella. Pero siempre hay alguna pertinencia contextual que se modifica por la acción del agente o interviene en la actividad. La situación está contextualizada e integrada también por objetos, mecanismos $\mathrm{y}$ artefactos y por los mismos agentes sociales intervinientes.

He comentado la centralidad que en la AS tiene los aspectos de relación con el contexto, los instrumentos y las interaccioenes con los sujetos, pero también la necesidad de considerar e integrar los elementos tanto cognitivos como prácticos u objetivables. Es el momento de insistir en éstos últimos, es decir, en los elementos cognitivos y en su distribución o conocimiento socialmente distribuido (CSD), que, como se ve, es un aspecto de la AS o viceversa.

\subsection{El conocimiento socialmente distribuido}

Con la expresión CSD se quiere resaltar la idea de que las percepciones, representaciones, memoria y, en general, las proyecciones y los procesos cognitivos están generados, extendidos y apropiados (distribuidos) diferencialmente entre los artefactos (o soportes) y entre los agentes, debido a que en el proceso de interacción, en tanto que dinámica y resultado, se entabla un necesario reconocimento y representación mutua, una interlocución, un intercambio y una negociación y una apropiación de los procesos cognitivos ${ }^{2}$.

2. Aunque no se pueden hacer equivalentes el CSD y/o la AS a lo que se ha dado en llamar la «inteligencia artificial distribuida» o "nueva inteligencia artificial», sí es verdad que ambas se oponen conjuntamente, como venimos insistiendo, a la inteligencia artificial clásica o simbólica y/o sistemas expertos. Los sistemas informacionales y/o automatizados que se reclaman de la nueva inteligencia artificial, básicamente las redes neuronales artificiales, los algoritmos genéticos, los conjuntos borrosos y de aproximados, el caos 
Para el CSD lo importante en la interacción no es tanto la cognición individual, sino la organización y distribución social, procesual y temporal de los componentes cognitivos entre agentes y artefactos en una situación real o natural (Cicourel, 1994), la actuación entre (de y sobre) todos los elementos supone e implica una modificación del conocimiento y de las representaciones; este aspecto es decisivo para alguno de los promotores del CSD. Supone según Hutchins una actividad de interacción en una tarea o actividad entre pocos o muchos sujetos en comunicación variable, es decir la AS. Esta visión conlleva la ruptura con un tipo de racionalismo que supone que lo cognitivo es una propiedad exclusivamente individual. La propuesta del CSD es la de una cognición que está «desparramada» entre los agentes y los artefactos manejados como resultado de la interacción habida. Evidentemente, dicha cognición distribuida depende de la posición de los sujetos participantes en la interacción social y/o cultural (Engeström y Middleton, 1996), esto es, es un conocimiento socialmente distribuido. Con todo, muchos de los autores que se reclaman de la CSD no acostumbran a ampliar excesivamente la extensión de los contextos sociales en las situaciones analizadas contrariamente al peso que, por ejemplo, para Cicourel tienen las instituciones y otros aspectos sociales en la configuración de dichos contextos. Para mejor caracterizar algunos de los trazos o rasgos importantes de la cognición distribuida, es importante presentar el contraste entre una visión clásica de los contenidos y procesos cognitivos y la del CSD; luego insistiré en la caracterización del CSD.

\section{Elementos alternativos entre el pensamiento simbólico propio a la IA clásica y el CSD. El razonamiento y conocimiento individual $y$ aislado versus el distribuido y situado}

El razonamiento o la inferencia son procesos cognitivos centrales. En una perspectiva clásica, las diferencias de los contenidos cognitivos y del "poder» inferencial y lógico entre los individuos y grupos se atribuye a diferencias en la capacidad de razonar. Pero si se vincula el conocimiento a los factores y situaciones de su producción, como lo son la actividad, otros sujetos e instrumentos, a la interacción y el contexto, se comprende que los resultados cognitivos queden percibidos, representados, memorizados y procesados de manera más distribuida y diferencial entre los elementos y sujetos intervi-

como sistema dinámico, etc. y la aproximación del CSD y/o AS mantienen una gran analogía en la flexibilidad y descentralidad de sus métodos, en la toma en cuenta de los procesos paralelos y no lineales, en la intervención de los aspectos situacionales y contextuales y en dejar de lado, en una primera instancia, el pensamiento simbólico, etc. Con todo, ambas, conocimiento socialmente distribuido y/o actividad situada, de un lado, y nueva inteligencia artificial, de otro, difieren, en mi opinión, por la introducción de la algoritmización, formalización, programación y recurso a la simulación en la IA y por la utilización de una metodología de tipo más cualitativo, etnográfica y/o antropológica en el CSD y/o AS. 
nientes. Esta distribución será cognitivamente diferencial también entre los sujetos intervientes, no sólo por sus experiencias socializadoras, sino también por su «lugar» en la interacción situacional, instrumentos manejados y la distribución en ella de sujetos e instrumentos. Precisamente avala esta posición el hecho de que la gente falla en problemas de razonamiento simples, justamente a causa del contenido y de la imagen situacional que hacen de sus planteamientos. Si la gente se equivoca en el razonamiento y en la inferencia no es tanto por el tipo de razonamiento, sino porque modifica contextualmente los elementos necesarios representacionales para el razonamiento. $\mathrm{Y}$ es que el razonamiento, aparte de su formalismo conectivo lógico, necesita esquemas cognitivos de referencia reales cual plataformas, plantillas, esquemas culturales con contenidos dados. En la medida que poseemos modelos culturales producidos en y por la contingencia y variabilidad del mundo, seremos más capaces de razonar adecuadamente sobre los acontecimientos y objetos que se refieren a dicho mundo. Demasiado frecuentemente el modelo de razonamiento de los psicólogos tiene como referencia a un individuo aislado cual máquina mental procesadora. Pero no se ha de olvidar que se razona más bien con referencia a esquemas culturales aprendidos socialmente, se razona perteneciendo o dependiendo de un grupo(s) y/o enfrentado a otro(s), interactuando por el lenguaje con un acervo más o menos común de referencias culturales y sobre todo se razona en situación (D'Andrade, 1989) ${ }^{3}$.

\section{La lógica causal y la teleología versus la relevancia contextual}

Parecida argumentación puede referirse a la relación entre la lógica temporal, causal y teleológica (como formas de lógica inferencial o deductiva) y el contexto de significados de la vida cotidiana de un grupo o sociedad. Se realiza una inferencia cada vez que se hace una aserción sobre la probabilidad de que suceda un acontecimiento o estado que no ha sido directamente observado. La inferencia está implicada en cada instancia cognitiva. Gran parte de nuestra riqueza cognitiva en la representación del mundo proviene del uso experimental de nuestra capacidad inferencial sobre hechos no observados o sobre intenciones. Pero aunque la inferencia como proceso cognitivo es un hecho incuestionable, lo es menos cómo y sobre qué base se hace. La dificultad proviene de no llegar a conocer (o suficientemente bien) qué partes y contenidos de la inferencia, por ejemplo, de las premisas, se dan como supues-

3. En una dirección un tanto paralela a la precedente, se puede establecer la diferencia entre: 1) un saber escolar con pretensión general y proposicional de contenidos, sin capacidad transportable a contextos contingentes y circunstancias locales, es decir, un saber asociado solamente al contexto de la clase escolar donde se aprende y que es precisamente donde y quien lo legitima y 2) un saber procedural necesariamente específico que es transportable a otros contextos, es decir, un saber práctico según Bourdieu. Esta distinción es vieja y ha dado pie a pedagogías, Montessory y Freinet, que aún parecen subversivas, alternativas o marginales (Vellard, 1994). 
tos o son implícitos o no están referenciados explícitamente interviniendo poderosamente, como intervienen en el proceso inferencial del discurso natural e institucional científico. Si hay ingredientes en dichos supuestos latentes de las premisas que son contextuales, situacionales y culturales, etc., además y más allá de los explicitados, es «lógico» que interfieran en el desenlace. Pues bien, estos elementos implícitos de las premisas tienen mucho que ver con la experiencia compartida, con los contextos de representaciones participadas, con la situación ad hoc. Si nuestros métodos de observación o nuestros principios metodológicos no son capaces de captar estos contextos cognitivos, es imposible que podamos atribuir a un grupo social o individuo una acertada o dada capacidad (o su negación) lógica, temporal, causal, teleológica inferenciales. La aproximación a lo implícito para poder hablar de capacidad inferencial de un pensamiento individual requiere la aproximación (previa, simultánea o a posteriori) a unos componentes culturales y sociales significativos del grupo observado en situación (Hutchins, 1981).

\section{El pensamiento simbólicolformal versus el CSD}

La afirmación central de la teoría de la AS y del CSD es que las actividades cognitivas se han de comprender sobre todo como interacciones entre agentes y de éstos con los sistemas físicos: en este sentido, se han de entender la producción del pensamiento simbólico y el uso de los símbolos. No es ésta la visión desde la teoría cognitiva de la IA clásicas. De acuerdo con la IA, los símbolos llenan la totalidad de la actividad cognitiva. De hecho, para esta perspectiva, el fenómeno cognitivo consiste en un conjunto de operaciones que construyen o modifican las estructuras simbólicas; esto es, cada proceso cognitivo es ni más ni menos un proceso simbólico. La situacionalidad de los procesos cognitivos no es decisiva ni crucial en su análisis. El punto de vista del CDS es el opuesto. Los procesos simbólicos son un caso especial de la actividad cognitiva, pero la situacionalidad es el ingrediente germinal y catalizador fundamental de la misma, lo que supone un tipo de cognición diferente al simbólico (Greno y Moore, 1993). Para precisar más las diferencias, doy cuenta telegráfica de algunas de las establecidas por Clancey (1993), si bien no tiene en cuenta la interacción social y se centra sólo en la cognitiva. Para mayor simplicidad y no ser repetitivo, pondré, al principio de cada epígrafe, la visión propia de los sistemas simbólicos en la línea de los sistemas expertos de la IA clásica versus, en segundo lugar, la del conocimiento socialmente distribuido y/o actividad situada.

1) Los procesos internos del conocimiento son modularmente independientes de la actividad, pudiendo percibir y razonar $\sin$ actuar $\leftrightarrow$ están codeterminados por la actividad situada dado el supuesto dialéctico de la relación. El aprendizaje es un efecto secundario y reflexivo, a partir de un chunking o fragmentación categorizada de secuencias de comportamientos en el tiempo y requiere la percepción $\leftrightarrow$ es un efecto primario que sucede en y para cada pensamiento, percepción y acción. 
2) La memoria es vista como estructuras esquemáticas o reglas almacenadas y como lugar de descripción del mundo y del comportamiento $\leftrightarrow$ es activación y reactivación, composición y recomposición de la actividad de nodos neuronales. Las representaciones son formas significativas internamente manipuladas $\leftrightarrow$ son formas creadas e interpretadas en y por la actividad; además, las representaciones externas son diferentes de la interpretación del Sí mismo. Las representaciones del conocimiento o modelos cognitivos son estructuras fisicosimbólicas almacenadas en el cerebro humano $\leftrightarrow$ son, al mismo tiempo, modelos del sistema del mundo y operadores para manipular dichos modelos y la actividad. El razonamiento, suplanta y precede al comportamiento inmediato $\leftrightarrow$ se origina por las secuencias de comportamiento en el tiempo.

3) Los conceptos son estructuras con nombres de términos lingüísticos, con descripciones asociadas a propiedades y con relaciones con otros conceptos, por ejemplo, los significados están simbólicamente representados y almacenados $\leftrightarrow$ son categorizaciones de categorías perceptuales, una maneras de coordinar la percepción y la acción; por tanto, no tienen una estructura formal inherente y no pueden ser inventariados. Así, significado y percepción son inseparables. La analogía aparece como rasgos trasladables o proyectados de representaciones conceptuales $\leftrightarrow$ son procesos de percepción y actuación que representan coordinaciones previas.

4) El comportamiento inmediato, según la teoría de los SS, está seleccionado desde posibilidades preexistentes ya preparadas $\leftrightarrow$ se trata de un comportamiento adaptado, compuesto, coordinado y siempre nuevo en un circuito sensorial y motor. El habla es el significado de enunciados y expresiones que están representadas antes de que sucedan $\leftrightarrow$ es el resultado de la dialéctica situacional entre su conceptualización y la actividad (Clancey, 1993).

La postura de la AS no es la de negar la existencia del pensamiento simbólico ni de la planificación y el razonamiento, sino de considerarlos como resultados secundarios además de integrados en la AS, aunque sin darles una primacía sobre la cognición de la actividad situada; simplemente son uno de sus productos (Suchman, 1993).

\section{Sistema experto, actividad situada y conocimiento distribuido}

La noción de expertise en la IA está connotada y relacionada con la idea de capacidad estable dentro de tareas bien definidas. Para que esta noción pudiera ser aceptada dentro de la AS/CSD debería contemplarse 1) como un proceso y una construcción discursivo que colaborase e interviniera en tareas y soluciones, cognitivas y fácticas, además de en interacción con las condiciones, y 2) validado ecológicamente por el contexto (Engeström y Middleton, 1966). La teoría de la AS/CSD mantiene una posición crítica con los siste- 
mas expertos y/o con el diagnóstico asistido por ordenador, en el sentido de que tales sistemas, descontextualizados, inflexibles, orientados y previamente planificados, no contienen siempre información suficiente sobre las condiciones locales ecológicas, sea en un diagnóstico médico, sea en otra actividad. Para ello sería necesario integrar en los sistemas expertos las relaciones contingentes con el entorno, los razonamientos del habla cotidiana, los procesos de comunicación in situ, etc. Cicourel (1994) lo ha tratado en su aplicación al diagnóstico médico.

La crítica al tipo de conocimiento propio de la IA clásica a partir de la posición de la AS/CSD es diversa: 1) sobre su objetivo de hacer contenido cognitivo y/o simbólico preplanificado y predominante con relación a la actividad en la vida cotidiana, 2) sobre su rigidez, que contrasta con la flexibilidad propia de conocimiento de la AS/CSD. Pero estas críticas no son homogéneas entre los adalides de la AS/CSD. Algunos rechazan la metáfora misma del ordenador; otros rechazan toda posible modelización computacional dudando que la inteligencia sea modelizable; otros enfatizan la incapacidad de la modelización para dar cuenta de ciertos aspectos de la inteligencia, por ejemplo, de los aspectos prácticos y experimentales, de los procesos de conocimientos modelizados o de la ausencia en ella de toda validez ecológica, en el sentido de Cicourel (1994). Desde mi visión, el razonamiento siempre se realiza en contexto. Precisamente el laboratorio y la escuela, por ejemplo, no son más que un tipo particular de contextos. Un sistema experto tendrá dificultades ¿̇insuperables? de presentar una lógica contextualizada, natural o de sentido común (Vellard, 1994).

\section{Características de la cognición distribuida socialmente}

Se trata de un conocimiento pragmático, puesto que su significado y sentido está dado en una comunidad de observadores más que por una especificación inicial planificada, formal o analítica. Construimos nuestro conocimiento del (y nuestras obligaciones con el) mundo externo a través de la práctica que es participada y situada. Al participar en múltiples comunidades de las que somos parte, en muchos tiempos y con diversos requerimientos, nuestro conocimiento y obligaciones se distribuyen y se estructuran.

Posee un carácter contingente, y no tanto planificado, finalista y determinado (Schuman, 1987; Agre, 1988). Precisamente la planificación no puede comprender la contingencia local que conforma el contexto y los agentes en toda su complejidad. La contingencia da a los acontecimientos un carácter indeterminista fundamental, en el sentido de que no siguen un conjunto-secuencia con desarrollo previo y lógico.

La cognición distribuida es también un entorno interpretado en una comunidad conjuntamente imbuida de significado (formando una unidad de actividad y cognición en interacción). La actuación se hace siempre a la luz de alguna lectura de la realidad que da a los agentes un comportamiento adecuado a la situación percibida (Leigh Star, 1996). 
La puesta en situación de la acción supone la puesta en juego de unos mecanismos de interacción que son de comunicación entre agentes y de éstos con los artefactos. La cooperación en equipo, en un continuo de tareas individuales e interactvias, pasa a ser una condición esencial y un efecto del desarrollo de la cognición distribuida. La coordinación es básica en los trabajos de Cicourel y Hutchins para la cognición social distribuida.

La exigencia del cambio de unidad de análisis es una primera condición para el análisis de la cognición en tanto que distribuida socialmente, y consiste en tomar como dicha unidad una entidad que supere la unidad individual. Para Hutchins el interés y la fecundidad del estudio del funcionamiento cognitivo y/o práctico de los instrumentos y sujetos de una cabina de un avión o de un barco está en tomar dicha cabina como unidad de análisis, para lo cual habrá que referirse también a las propiedades cognitivas de los pilotos individuales (Hutchins y Klausen, 1996). Las propiedades comportamentales de este tipo de unidad de análisis lo son en términos de estructura y de proceso de las representaciones y actividades internas a dicha unidad. Estos sistemas, más extensos que el individuo, tienen propiedades cognitivas que no son reducibles a las propiedades cognitivas de las personas individuales (Hutchins, 1995). Este cambio de referencia a unidades más globales y envolventes no es nuevo, lo nuevo es considerar la relación de los agentes con el entorno, la función interviniente y interactiva de los artefactos, la propagación por ellos y los agentes de las representaciones y de los procesos (Norman, 1993).

La cognición distribuida está mediatizada por los artefactos. En la perspectiva que consideramos no se puede concebir una dicotomía entre acciones comunicativas y acciones instrumentales. Toda práctica es comunicativa por y con los artefactos: sistemas notacionales, automatizados e informacionales. Estas tecnologías de información y/o inteligentes muestran también los dos aspectos que caracterizan a todo artefacto: el instrumental y el semiótico con sus niveles de mediación más o menos complejos.

El trabajo de equipo asistido por tecnologías, en particular si son complejas, requiere una orientación metodológica y conceptual para que el análisis no se centre sólo sobre las relaciones agente versus sistema, sino también, y sobre todo, sobre las interacciones entre varios agentes que han de coordinar las actividades y los útiles diferentes. La aptitud para coordinar actividades y el trabajo de interpretación y percepción se apoyan en la organización social; es decir, sobre un conjunto de competencias y de prácticas que permiten a los diferentes agentes identificar las actividades de cada uno, y por ello, actuar de manera apropiada. Esta forma de organización es lo que puede definirse como cognición distribuida; esto es, como un proceso por el cual los diferentes sujetos se representan, razonan, se orientan hacia y realizan de manera grupal un conjunto de tareas y actividades, Hutchins (1989), actividades que se inscriben en un cuadro cultural o en un contexto social particular. Dichosamente, las investigaciones en sociología y en la tradición del trabajo etnográfico, cada vez más numero- 
sas, van ofreciendo medios metodológicos necesarios para una exploración de las carecterísticas sociales y situacionales del trabajo cooperativo (Heath y Luff, 1994).

\section{El contexto en la perspectiva de AS y/o CSD}

Trataré en este apartado de algunos de los contextos o planos de inserción que son más relevantes para la teoría AS y/o CSD. Los autores se focalizan o consideran aquéllos que son más próximos a su especialidad de origen o más pertinentes para dar cuenta de la actividad situada. Una cierta clasificación en planos nivelados, envolventes y en relación dialéctica es la dada por Lave (Agree y Shrager, 1991): 1) El sistema semiótico o estructura social. 2) El individuo y su actividad en la "arena» o locus. 3) La persona en actividad en situación. 4) La actividad concreta que se realiza. Esta taxonomía guarda un cierto paralelismo con la de Layder (Layder, 1993) (Lozares, Martín, López, 1998): 1) Historia, poder y contexto o estructura contextual formal. 2) Marco o composición o estructura contextual sustantiva. 3) Actividad situada o estructura de la interacción. 4) El sí mismo o Self. Pero más que recorrer estos niveles, seguiré un criterio de contextualización más sectorial describiendo los más comunes en los análisis de AS/CSD. A los contextos que describo se puede añadir un cuarto de naturaleza más estructural o sociohistórico, que es el propio de la macrosociología, considerado por los estructuralistas y otras tendencias macro muchas veces como exclusivamente identificado con la sociología. Este nivel adicional corresponde a los primeros niveles de Lyder y Lave ${ }^{4}$.

4. El campo de las actividades de trabajo es uno en el que más se ha tenido en cuenta este contexto tan global. Se dan en este sentido, en las ciencias sociales y psicológicas, dos tradiciones. La primera, más macrosocial, considerando, por ejemplo, el impacto del desarrollo tecnológico en las capacidades de los trabajadores y en la organización del trabajo según diferentes marcos teóricos y sociales, taylorista, fordista, postfordista, producción flexible o los cambios históricos en las pautas y posición social del trabajo. En la segunda, se consideran más bien temáticas o aspectos que quedan fuera de aquella visión macro, tanto en términos analíticos como conceptuales, por ejemplo, la agencia humana implicada en las acciones e interacciones cotidianas que la gente realiza en el trabajo, en diferentes posiciones y situaciones organizativas y, sobre todo, negociadas, realizadas y construidas localmente. Esta dicotomía se ha centrado en diferentes disciplinas: la primera, en la literatura de la sociología del trabajo y, la segunda, en la de la AS. De todas maneras, está apareciendo una tendencia y una preocupación crecientes sobre las transiciones y los cambios en el trabajo, la intervención de la tecnología y los cambios organizativos en la producción y, sobre todo, en el trabajo cooperativo y de soporte con ordenador. Así, los límites disciplinares se están rompiendo para contener áreas de investigación en que los referentes pueden ser, por ejemplo, sobre la manera en que las prácticas humanas emergen en el trabajo que, no obstante localizadas, se hacen inteligibles socialmente, sobre la cognición socialmente distribuida, sobre la continuidad y el cambio a partir de las prácticas directas de trabajo. 


\section{El contexto tecnológico}

He insistido en la importancia que, para los que se reclaman de la AS/CSD, tiene la interacción con los artefactos, máquinas informacionales, etc. Cicourel y también Hutchins establecen una distinción entre 1) tecnologías con capacidad de tratamiento de la información inherente al dispositivo y que deben ser evaluadas e interpretadas por uno o varios agentes (por ejemplo, la pertinencia clínica de la temperatura dada por un termómetro de mercurio o eléctrico debe determinarse y ponerse en acto por el médico) y 2) otras tecnologías que, con una cierta capacidad cognitiva, tienen una función más interlocutiva con los recursos cognitivos del que realiza la tarea. La entidad y peso de la influencia de ambos tipos de artefactos en la interacción es diferente. Las primeras tecnologías, dado su carácter más instrumental, permiten al agente una manera de actuar más autónoma e independiente con relación al artefacto; las otras, con más peso cognitivo incorporado, tienen un rol más autónomo y de interlocución más directa con el agente. Pero ambas participan en el conocimiento distribuido, sea un quirófano, una cabina de avión, un cuarto de control de tráfico o de producción continua, una sala de fotocopiadoras, por citar algunos de los casos estudiados. Por ejemplo, la percepción de la salud de un paciente está subordinada a las tecnologías que o bien suministran información o bien facilitan interlocutivamente la intervención (Cicourel, 1994). Por tanto, para construir, utilizar y estudiar los artefactos como parte del entorno activo y cognitivo, se ha de tener en consideración o bien su naturaleza instrumental o bien interactiva. En el primer caso el acento se pone en la percepción de su configuración espacial y adaptabilidad a su función; en el segundo, se dirige a la comprensión de la acción y comunicación interactiva.

Es importante en este análisis considerar también la vinculación entre actores y contexto tecnológico, por ejemplo, Huchins lo realiza, entre otros contextos y profesiones, en el marco cognitivo del sistema de una cabina de avión. Según él, la investigación corriente en psicología cognitiva suele tener como objetivo la explicación de las propiedades del proceso de información de los individuos (pilotos), tratando de inferir lo que está dentro de su mente. Por ello se trata de seleccionar cuidadosamente una investigación o experimento, de tal manera que sea más accesible evidenciable y validable el estudio de determinados estados internos informativos y, en general, cognitivos a los individuos. Pero si se toma, por ejemplo, la cabina de pilotaje de un avión o de un barco como unidad de análisis, podemos ver dentro de ella y observar directamente muchos de los fenómenos, en particular, las representaciones que están dentro del sistema de la cabina pero fuera de las cabezas de los pilotos. Nos permite conocer las propiedades cognitivas de tal sistema (por ejemplo, sus propiedades comportamentales en términos de representaciones internas), sin necesidad de entrar a profundizar en los procesos internos que operan en los actores individuales. Por tanto, más que proyecciones o introspecciones psicológico-cognitivas directas en los pilotos obte- 
nemos la mapificación y conceptualización del sistema cognitivo dentro de una nueva unidad de análisis, la cabina como una totalidad.

Dada la imprescindible interface de los instrumentos o artefactos con los sujetos, es también necesario ver el tipo de conflicto y consistencia que puede originar el diseño y la finalidad del artefacto. El mayor conflicto se da entre un diseño o una configuración centrado en sus propiedades formales y el centrado en el usuario. La consistencia llamada de interface, que equivale a un diseño aislado sin considerar su uso y su usuario, puede tener dificultades de aplicación 5 .

\section{El contexto profesional ${ }^{6}$}

Este contexto se superpone en buena medida al que trataré a continuación en 2.3., el institucional, pero lo considero aparte porque es más «tratable» en la acción situada y por su importancia en la literatura. El contexto profesional o profesión proviene de la interacción de las personas en un entorno o situación, en general, muy pautado, homogéneo y determinado. Agree y Shrager (1991) lo examinan en su investigación sobre la fotocopiadora dando poco peso a la interacción específicamente social con otros actores, aunque hagan al principio de su exposición una digresión teórica sobre la evolución del trabajo. Para ellos la línea maestra que sintetiza tal contexto, y lo generalizan a los contextos industriales, consiste en la construcción cultural de la reificación de la aceleración/velocidad productiva ${ }^{7}$.

Se denomina "construcción de la profesión» a las prácticas, entre otras las discursivas, a la lógica, reificaciones ideológicas, maneras de hacer, etc., que se desarrollan y se usan por los miembros de una profesión para configurar los acontecimientos o acciones en ella. El proceso de realización de dichas prácticas crea objetos de conocimiento que llegan a ser modelos y prototipos de destreza, habilidad y astucia, artefactos, conocimientos, maneras de ver y hacer, cuerpo de expertos, etc. que las diferencia de las de otras profesiones. La profesión vie-

5. Para Grundin (1989), el objetivo de una consistencia interface es una ilusión que no funciona. Grundin habla de tres tipos de consistencia o de consistencia en tres sentidos diferentes: 1) la consistencia interna del diseño del aparato consigo mismo que denomina "consistencia interface»; 2) la consistencia del diseño con otros diseños, interface externos familiares al usuario, y 3) la consistencia externa analógica o correspondencia metafórica de un diseño, a los rasgos del mundo más allá del dominio del objeto en sí mismos. Para Grundin se ha de conocer y dar primacía, en la interface, a las tareas de los usuarios. Hutchins insiste en que el funcionamiento de los mecanismos del sistema se ajusten a los pensamientos y objetivos de los usuarios.

6. Este contexto corresponde, de alguna manera, a los niveles 2 y 3 de Lave y Layder.

7. La «velocidad" productiva se ha convertido hoy día en la medida y piedra de toque de la capacidad del trabajador y en un componente importante de la concepción popular del trabajo. No tiene imortancia solamente a través de la compresión del trabajador, sino que está implícita en el mismo diseño de los instrumentos, por ejemplo, en el caso de las fotocopiadoras, Agree y Shrager (1991). 
ne a ser el conjunto de métodos usados por los miembros de una comunidad que construyen los acontecimientos que estructuran la vida profesional ${ }^{8}$.

\section{El contexto institucional ${ }^{9}$}

Cicourel insiste en la pertinencia e importancia social de este contexto, aunque no se considera suficientemente en los análisis de AS/CSD, debido, entre otras cosas, a la dificultad de observarlo y examinarlo a través de las actividades y del discurso. Sin embargo, es en los niveles institucionales donde se manifiestan las estructuras de dominación y autoridad. Con ello Cicourel introduce una dimensión social en este tipo de estudios, que, en general, son más localistas y cognitivos aunque contextualizados. El contexto institucional actúa sobre las actividades locales o acción situada a través de normas colectivas que orientan a las personas hacia tareas específicas, modelizando sus actividades y serializando (o vulnerando) las pautas de interacción, etc. Algunas vías por las que se manifiesta el marco institucional a través de las actividades y/o del discurso son, por ejemplo, por la experiencia de los participantes que trabajan juntos en un mismo marco institucional, por las representaciones mutuas de los agentes y por las responsabilidades recíprocas, el conocimiento y la toma de decisión objetivados en títulos, responsabilidades, tomas de decisión organizativas, consejos, etc. La posición en la estructura institucional de los individuos (sea en las divisiones funcionales o sociales, sea en las verticales u horizontales) influye en el acceso a la información, en el apoyo y consenso del personal y en la comunicación interna y externa ${ }^{10}$.

8. Goodwin (1994) lo examina en una excavación arqueológica y en un juicio a partir de las actividades de codificación, construcción de indicadores y presentación y elaboración de gráficos, aunque para él el peso discursivo es mayor que el de la cognición. La construcción de la profesión que realiza (y estudia en) su alumna arqueóloga sin saber bien, a partir de su artículo, si se debe a lo aprendido en las clases del profesor o a su progresiva habilidad del aprendizaje in situ. De todas maneras, estudia cómo en situaciones diferentes se desarrolla un discurso común y unas prácticas consecuenciales y extensibles a la profesión. Cicourel (1994), muestra este mismo contexto profesional estudiando las actividades y los intercambios verbales entre médicos o entre éstos y el personal de cuidado. Esclarece las maneras en que el contexto social constituye la base de la elaboración de los diagnósticos medicales y la pertinencia de la información y credibilidad de las fuentes. El contexto profesional y/o la construcción de la profesión incide en, y se construye en parte por, la relación entre los elementos del sistema social que intervienen en el diagnóstico médico, los medios o sistemas de ayuda expertos y la toma y formalización de las decisiones.

9. Este contexto corresponde al 2 (arena), de Lave y también al 2 (estructura contextual sustantiva) de Layder.

10. Cicourel lo analiza en los hospitales. Por ejemplo, la profesión hospitalaria se construye institucionalmente, entre otras formas, por redes interpersonales que influyen en el funcionamiento cotidiano (comunicaciones, consultas, representaciones, autoridad y mandatos), posibilitan una resolución distribuida de los problemas, reflejan las estrategias cognitivas distribuidas, el estatus y las relaciones entre médicos y de éstos con otros miembros del personal (enfermeras, cuidadores, camilleros, etc.). (Cicourel, 1994). 


\section{PARTE \\ BASES TEÓRICAS Y METODOLÓGICAS Y ORIENTACIONES PARA LA INVESTIGACIÓN EN LA AS/CSD}

\section{Una panoplia más o menos convergente de teorías que provienen de diversas disciplinas}

Aunque en el propio desarrollo de la AS/CSD he ido desarrollado un cierto bosquejo disciplinario como prolegómeno a una incipiente teoría de (o aproximación teórica a) la AS/CSD, lo que prevalece es, sin embargo, una gran heterogeneidad y diversidad de origen y contenidos. Por ello daré un panorama rápido más como evocación y referencia que como intento de síntesis, tampoco los autores que se reclaman de la AS/CSD acostumbran a hacerlo.

Algunos autores (Leigh Star, 1996; Agree, 1993; Schuman, 1987) sitúan las bases teóricas de la AS/CSD en teorías sociológicas como el pragmatismo, el interaccionismo y la etnometodología.

Otra de las corrientes de pensamiento de la que se reclaman algunos autores de la AS/CSD es la perspectiva dialéctica. Esta aproximación tiene su origen en psicólogos y filósofos marxistas (Raeithel, 1996), en el estudio detallado y cualitativo de la actividad y en una visión comprensiva de lo cultural y social dentro de la psicología (Vygotsky, 1978; Bakhtin, 1981, 1984). Pero Lave (1988) es quien la ha desarrollado más específicamente. El marco de Lave se integra en esta tradición. en particular en el análisis de la estructura detallada de las actividades rutinarias, y proporciona una conceptualización más intrincada y dinámica de la actividad y de la mente humanas. Para él una relación dialéctica entre dos entidades supone tres condiciones: 1) que las dos entidades estén en interacción en un tiempo extenso; 2) que esta interacción ejerza una continua influencia sobre ambas entidades, y 3) que, como resultado de esta influencia, las entidades se definan necesariamente en términos de su relación mutua, como se ve una visión muy laxa de la dialéctica. A esta condición la denomina «constitución recíproca». La actividad y el aprendizaje proceden de la influencia recíproca entre actores y la situación organizada socialmente. La relación dialéctica se realiza entre los planos siguientes: 1) entre el sistema semiótico o estructura social: mientras los tres siguientes niveles de análisis se refieren a la organización de una actividad particular, éste, más envolvente, describe la estructura social dentro de la cual se organiza la escena social; ii) la persona actuando en una «arena» (organización, institución, supermercado): sitúa la actividad en un contexto social más amplio que los dos siguientes, contemplando la relación dialéctica entre la persona y un locus de actividad producto, ella misma, de fuerzas estructurales sociales más amplias; 3) la persona en actividad o situación donde se reespecifica la actividad en términos de una relación dialéctica entre la persona en la actividad y la situación en la que la actividad toma lugar, y 4) la actividad concreta que se realiza que se describe de una manera literal, tomando como base la evidencia disponible. 
Otra interpretación que guarda un paralelismo con la dialéctica es la de autorregulación semiótica de Raeithel (1996). Los seres humanos son capaces de crear por sí mismos nuevas posibilidades de acción, operando sobre representaciones semióticas en las que se incluyen instrumentos, lenguaje, escritos y sistemas de signos formales a través de formas (sintaxis), de sus acciones y por las similitudes (contenido y relación) entre antiguas y nuevas posibilidades. En la teoría simbólica estos signos se interpretan como absolutamente internos al sujeto epistémico, como por ejemplo los sistemas simbólicos de Newell y Simon ${ }^{11}$.

Tal y como voy insistiendo, la teoría de la AS/CSD está por elaborar. Para Leigh Star (1996), la Activity Theory debería ofrecer una aproximación a la comprensión de la especificidad histórica y material de la cognición, al mismo tiempo que un alejamiento de todo contagio idealista y determinista en la concepción de la percepción y la cognición. Clancey (1993) resume la teoría de la AS en una serie de proposiciones que son más bien unos enunciados de oposición radical a la visión simbólica. 1) El rechazo de una concepción o modelo de memoria como almacén o archivo que tiende a ver la actividad como ejecución de reglas o mandatos; la información como preconfigurada, seleccionada o filtrada desde el entorno y los conceptos como descripciones amontonadas cual definiciones de diccionario. Este modelo archivero de representaciones previas y disponibles ha hecho que la ciencia cognitiva no se haya dedicado suficientemente al estudio de cómo la gente crea dichas representaciones en el día a día; ídem de la comprensión, el significado, el habla, el conocimiento, etc. 2) Los modelos de almacenaje ven en el aprendizaje un fenómeno secundario. Pero para la AS lo específico del comportamiento cognitivo humano no es una memoria que guarda ordenadamente categorías, sino el aprendizaje de las maneras de hablar, de ver, de relacionarse y, en general, de comportarse coordinadamente. 3) El aprendizaje sucede en y por cada acto y no precisamente a partir de significados primitivos o de recetas que siguen reglas o estructuras discursivas. 4) La integración de la percepción, del pensamiento, de la actividad y de la organización es dialéctica y se lleva a cabo por subprocesos de coordinación coherente. La percepción es siempre un acto de percibir, es interactiva e implica siempre

11. El trabajo central de Bakhtin es la noción de organización dialógica del lenguaje que va más allá de una connotación de diálogo entre diferentes hablantes para invocar (y extenderse a) los entornos alternativos domésticos culturales, sociales y lingüísticos con los que dialoga y se confronta el habla. En la tradición materialista de Vygotsky (1978), el lenguaje y otros sistemas de señales o funciones simbólicas se tratan de la misma manera que los otros instrumentos de la actividad. Pues bien, a la misma conclusión llega el filósofo semiótico Peirce. Esta similitud es debida posiblemente a una interpretación realista y objetivista de las ideas como señales y conceptos, en el sentido que tienen una existencia real y física en presencia del actor y a la claridad y categorización concreta y definida de las interpretaciones. Por ello los signos pueden usarse para el control de la propia acción. Son también, desde un punto de vista práctico, los instrumentos de la voluntad del actor en Vygotsky. 
aspectos sensoriomotores. 5) La práctica no se puede reducir al pensamiento o a la teoría, ni es reducible a (o proviene de) un conjunto de leyes comunes, gramáticas y esquemas de comportamientos almacenados en cerebros individuales como un lugar de control de nuestra actividad. La capacidad de coordinar nuestras actividades sin la mediación de teorías es, al contrario, el fundamento de nuestra capacidad para reconocer, acomodar los cursos de la acción y teorizar sobre sus similitudes ${ }^{12}$.

\section{Orientaciones metológicas generales en las investigaciones sobre la AS/CSD.}

Como vengo insistiendo, la AS/CSD se nutre teórica y metodológicamente de la etnografía, de la antropología cultural y cognitiva, la sociología y la psicología cognitiva. El supuesto central de esta aproximación consiste en que en cada situación, actividades en equipo profesional u otro entorno o comunidad cultural, hay un sistema propio de explicación del mundo que se basa en sus prácticas. Por ello es decisivo que los científicos se desalienen de sus propias perspectivas familiares para alienarse, alinearse y aliarse con lo que a primera vista les parece ajeno (Raeithel, 1996). Hutchins (1981) insiste en que, en consecuencia, el conocimiento cultural de los equipos o grupos estudiados permite inferir y dar sentido a los acontecimientos y sus prácticas. Es decir, en la investigación sobre actividades y/o comportamientos situados, máxime si la situación no es familiar, parece imprescindible una metodología etnográfica que tenga en cuenta los significados atribuidos por los propios participantes, proporcionando así el nexo interpretativo para construir la teoría de la cognición distribuida (Hutchins y Klausen, 1996). De todas formas, no se trata de una exigencia extraordinaria, pues incluso las prácticas de los científicos naturales están basadas a veces en una conexión, aceptada implícitamente, de los signos percibidos subjetivamente y de los efectos del fenómeno analizado. En el campo de la etnografía, y en general en el de las ciencias sociales, esta conexión ha de ser por sí misma parte del fenómeno observado. Si se establece este diálogo o intercambio, que puede revestir varias formas, entre el (o los) miembro(s) de la comunidad de actividades observadas y los observadores, aparte de desbloquear una ruptura improductiva desde el punto de vista de la investgiación, permite al observador situarse dialógica y familiarmente en las posiciones y situaciones que "ocupa» el observado, por ejemplo, rememorando situaciones empíricas de parecido cariz, manifes-

12. Opuestamente a todas las teorías reseñadas, la teoría cartesiana y simbólica ve el mundo y la mente como realidades separables analíticamente como, por ejemplo, se da la diferencia entre datos y programas, entre software y hardware. Uno de sus supuestos básicos es que la percepción y el razonamiento son posibles sin actuar. Esta dicotomía se produce porque la deliberación se opone a (y la arquitectura está disjunta de) la coordinación de la percepción-acción inmediata (Clancey, 1993). 
tando al observado los objetivos de la investigación, transmitiendo los resultados o la recogida de información, etc. Y, por parte del observado, interpretar y expresar la práctica realizada, dialogar con el observador sobre la recogida de la información y los resultados (Raeithel, 1996).

Cicourel sugiere la necesidad de poner a punto una metodología a la vez cognitiva y sociolinguística fundada sobre una etnografía de terreno consultando los análisis con los mismos informadores, de tal forma que suministren interpretaciones tanto del discurso tenido y de las actividades tecnológicas asociadas a las tareas como de los intercambios verbales y escritos de la observación. Al mismo tiempo, siguiendo a Cicourel, conviene tener presente, también en la interpretación, la división de trabajo institucionalizado que define los tipos y la trastienda de los acontecimientos, la expertise atribuida a las personas que ocupan puestos particulares y los objetivos organizativos. Además, la buena marcha de la interpretación y del análisis exige un constante feed-back entre los diferentes agentes, controlando y evaluando sus actividades (Cicourel, 1994). En el apartado precedente insistía en la necesidad, dentro de la AS/CSD, del cambio de unidad del individuo a un sistema más abarcante en el que se comprendan tanto los otros agentes de la acción como el entorno de los artefactos instrumentales informacionales o de comunicación. Pues bien, la recentración de la que hablo va en la misma dirección (Hutchins, 1995).

Como acabo de afirmar, la AS/CSD se inscribe en las corrientes etnográficas, cognitivas y antropológicas. Por tanto, muchos de los métodos de estas disciplinas lo son también de la observación, el análisis y la interpretación de la AS/CSD. He aquí, muy concisamente, algunas de las características de estos métodos más pertinentes en la investigación sobre la AS/CSD. 1) La sucesión cíclica e interactiva de los métodos que incluyen conversaciones, entrevistas, detallados documentos y diálogos transcritos generados en el proceso de la acción, el rescate de los aspectos más sobresalientes de los acontecimientos y su transcripción en un lenguaje preciso, de tal forma que puedan ser reconstruidos. 2) Un sistemático esfuerzo en la búsqueda de casos con la mayor variabilidad posible, para cubrir todas las perspectivas y características de los actores guiados por un muestreo teórico, no hay lugar al muestreo aleatorio. El ruido, incluso el no deseado y/o inesperado, puede ser un dato importante y central. 3) Los informes etnográficos han de contener diversos elementos, pero también una organización interna: los comentarios sobre la estructura y la función de las diferentes partes observadas alternan con extractos literales de los documentos originales, que están seleccionados por su función ejemplar. Se han de acompañar con descripciones del trabajo y de las prácticas de los investigadores y de su acción en equipo. 4) La aplicación de los métodos etnográficos a la investigación comienza por contemplar cada grupo de trabajo u organización como una comunidad ajena, pero cuyo modelo e interpretación del mundo y sus prácticas se han de reconstruir desde expresiones y modos de personas situadas en la acción. 5) Hay autores que aplican las técnicas del análisis conversacional al estudio de la inte- 
racción humana, siempre con el supuesto de reconocer que la observación y dicho análisis se realiza dentro de un mundo formado por las actividades de los demás. De esta forma exploran las interferencias y los complementos que pueden darse entre el análisis conversacional, la teoría de la AS y/o CSD a partir de los conceptos de Vigostky y Leontev y las discusiones actuales sobre cognición distribuida (Goodwin y Goodwin, 1996).

\section{Pautas y esquemas de referencia observacional y analítico- interpretativos y algunas orientaciones técnico-observacionales}

Trato de presentar en este apartado, de una manera más bien esquemática y siguiendo la lógica de los dos precedentes, algunas orientaciones extraídas de diversas investigaciones en el campo de la AS/CSD que permitan tener algunas referencias, pautas o modelos más precisos para desarrollar la investigación en la AS/CSD, sea en la recogida de la información, en el análisis o en la interpretación. Me refiero a algunos métodos y técnicas, y no tanto a su secuenciación en fases de la investigación

Con relación al contexto institucional y/o la construcción de la profesión. Veamos algunos aspectos de los contextos institucional y/o profesional pertinentes en la AS /CSD. Cicourel los contempla en la institución hospitalaria. 1) Es fundamental la información recogida sobre el trabajo en grupo o en equipo (por ejemplo, en un laboratorio o en un trabajo de campo), sobre todo las comunicaciones verbales en las que se basan las tomas de decisión y la eficiencia profesional; el discurso profesional no va de sí, sino que se ha de considerar detenida y directamente. 2) En el contexto institucional (por ejemplo hospitalario) es importante examinar: a) el marco institucional (por ejemplo las normas colectivas) y otros contextos más localizados y negociados, todos ellos orientan a las personas y modelan las actividades en espacios físicos, momentos y tareas específicas; $b$ ) las tareas asociadas al diagnóstico y al tratamiento en los servicios de consulta externa de los hospitales, ya que son una ilustración detallada de la estructura de las relaciones de autoridad: médicos jefes, residentes, asociados, ayudantes, enfermeras, cuidadores, camilleros. 3) Aunque los médicos basen sus diagnósticos y tratamientos en los resultados de las tecnologías, estas actividades dependen de la organización social de los centros y de microprocesos socialmente estructurados; por ello es importante tener presente la organización vertical y horizontal de las estructuras de autoridad, ya que pueden constituir una barrera social para la aplicación válida de tecnologías y de expertise. 4) Las redes interpersonales que reflejan el estatus y las relaciones de los agentes son una fuente de poder y conocimiento distribuido de primer orden y han de ser examinadas con atención. Estas redes pueden constituirse a través de las consultas entre expertos, entre médicos, etc., a través de la distribución y resolución de problemas y de la división del trabajo. 5) Un material informativo de primer orden está constituido por los productos de mediación elaborados por los agentes, sea como información o decisión (por ejemplo, el dossier medical es una mez- 
cla de informe técnico y de notas cuasi caóticas de los diferentes miembros que han intervenido en el diagnóstico). La manera de interpretar el dossier por el personal es el reflejo de un conjunto complejo de relaciones y de atribuciones socioprofesionales que concurren en la distribución de competencias cognitivas. 6) Los individuos que trabajan en colaboración en un medio institucional adquieren representaciones mutuas, entre otras: de la autoridad, del renombre y de la credibilidad de los actores y de los mismos instrumentos que, además, se activan y se modifican continuamente. Dado que la manera de evaluar los diagnósticos está en función de la precisión de dichas representaciones, su estudio aparece decisivo.

Con relación a las tareas y al trabajo cooperativo. Heath y Luff examinan las relaciones de cooperación entre un controlador/regulador de tráfico del metro y el informador al público desde el mismo puesto de mando. Las características informativas que contemplan en esta relación son las siguientes: 1) El flujo continuo de informaciones verbales y no verbales entre regulador e informador. 2) La capacidad para controlar y corregir sus actividades respectivas. 3) La puesta al día de la información y su transmisión a los conductores o al público o al entorno inmediato. 4) La inteligibilidad mutua de cada situación. 5) La coordinación de tareas y de las actividades de comunicación verbal y no verbal socialmente organizadas: a) la manera como las tareas y las responsabilidades específicas (incluso las que parecen individuales y privadas) están organizadas interaccionalmente; $b$ ) el desarrollo de actividades que corresponden a tareas no predeterminadas profesionalmente; $c$ ) la manera de participar y de tomar parte en las actividades de los otros, como, por ejemplo, la distribución de la atención e informacion. Es su análisis Heath y Luff observan cómo las diferentes actividades específicas del regulador y del informador no les impiden participar en y sorprender la conversación y las actividades de los otros colegas (Heath y Luff, 1994).

Con relación al entorno instrumental o de artefactos, la interacción de los agentes con ellos y las pautas cognitivas en un medio de trabajo. 1) Una primera observación se centra en el tipo de tecnología/artefactos disponibles y/o utilizados y en el rol que tienen en la disposición e interacción del entorno. La distinción influye en el planteamiento de la investigación. La clasificación que hemos hecho anteriormente siguiendo a Cicourel, Hutchins y Conein es fundamental. Es decir, entre a), por un lado, las tecnologías que tienen una capacidad instrumental de tratamiento de la información y de explotación y exploración de los recursos cognitivos del que realiza la tarea y b), por otro lado, aquéllas que son interactivas y de cooperación asistida, cuyo acento está en la comunicación y las autómatas con capacidad organizativa situacional. 2) Refiriéndome más directamente a la interacción, es importante tener presentes: a) Las observaciones e indicaciones informativas o de decisión o de control, resultado de la actividad del agente y de los instrumentos informativos: tablero de circulación en salas de control de tráfico; el dossier de diagnóstico y el tratamiento médico. b) Las actividades observables de los agentes: reflexiones en voz alta; comunicaciones habladas; 
juramentos; movimientos corporales, de manos, dedos, etc. 3) Es importante también la lectura de los instrumentos que dan información y registro de las representaciones, memorias internas y externas y las interpretaciones y las descripciones de los procedimientos cognitivos distribuidos entre los miembros del equipo. Por ejemplo, en la cabina de un avión a) los indicadores de velocidad, posición, viento, altura, inclinación de las alas en los datos del descenso, aproximación final y aterrizaje; $b$ ) la descripción cognitiva de dichas indicaciones, representaciones de velocidades y procesos dentro y fuera de la mente de los pilotos. Hutchins denomina "memoria del sistema» a esta representación del entorno y del conjunto de la cabina (memoria de representaciones de procedimientos y cogniciones); consiste en un estado representacional, dentro y fuera de la cabina, que es guardado y usado para organizar actividades consecuentes. Ni en esta memoria del sistema, ni en las tareas y las distribuciones cognitivas de los pilotos, ni los componentes de procedimientos se encuentran exclusivamente en los pilotos o en los instrumentos, sino en la interacción mutua. 4) Tampoco la actividad de fotocopiar es exlusiva del individuo o de la fotocopiadora, sino de la interacción entre individuo y artefacto, como lo analizan Agree y Shager cuando observan dicha actividad en una persona sin formación previa más que la genérica del protocolo corriente de cualquier fotocopiadora. El individuo cambia en el tiempo sus relaciones con la fotocopiadora comprendidas en términos de actividad autoorganizada a partir de la experiencia acumulada en los procesos en situación, y no a través de secuencias planeadas desde el exterior. En dicho estudio se fijan en: a) la localización de los rasgos de las tareas relevantes; $b$ ) el registro físico de la relación entre la persona y la fotocopiadora; $c$ ) los cambios de actividad (por ejemplo, se comienza a hacer fotocopias de una manera y se termina de otra, el arreglo del papel, de la posición, etc.); d) el proceso de aprendizaje. La relación de la persona que fotocopia y su entorno pueden comprenderse mejor a partir de una interacción dialéctica ${ }^{13}$. Proponen, siguiendo esta orientación, los siguientes pasos y/o referencias: a) El examen de la estabilidad y los cambios de las situaciones recogidos en términos de las relaciones relevantes entre la persona y el entorno. A partir de aquí se puede hablar de la estructura de la actividad. b) La comprensión de la relación de la persona con la fotocopiadora en términos de autorregulación, más visible cuando se da alguna disfunción que rompe la ligazón evidente y/o conseguida: es el momento de examinar las condiciones bajo las cuales se realiza la actividad. c) La caracterización del aprendizaje también en términos relacionales. d) El proceso supone que ambos, individuo y su entorno, van cambiando (Agree y Shrager, 1991). 5) Para terminar y como resumen he aquí

13. Agree y Shrager se oponen así al behaviorismo y al mentalismo y sus tendencias correspodientes: el primero, a atribuir la iniciativa del proceso al entorno y, el segundo, al organismo. Los autores no hablan de dos lógicas, una residente en el individuo y otra en la fotocopiadora, sino más bien de la relación entre ambas para llegar a producir efectos conjuntos (Agree y Shrager, 1991). 
algunas indicaciones generales sobre lo que se puede observar, interpretar y analizar en la perspectiva de la AS/CSD en un medio tecnológico: a) la formación y planificación de la actividad y sus tareas correspondientes, así como su representación, valoración y violación en su ejecución, b) la distribución del acceso a la información, $c$ ) las trayectorias de la información y su distribución y almacenaje, d) la intersubjetividad en los procesos de comunicación, la computación, propagación y transformación del estado representacional del sistema, e) la distribución de nuevas tareas y vi) la memoria del estado de los artefactos.

Con relación a la recogida de información. Doy cuenta a continuación del proceso de recogida de información que Hutchins lleva a cabo en la cabina y en la tripulación de un avión. 1) El análisis comienza con un vídeo y una grabación de los acontecimientos en la cabina. Es una primera representación de lo que pasa en ella, aunque algunos aspectos de la situación quedan fuera debido, por ejemplo, al ángulo de la cámara, al campo que abarca y al color, si es el caso. El vídeo facilita el seguimiento de la organización de la actividad como un proceso de interacción entre agentes y agentes-instrumentos desplegado temporalmente en su secuencia real: preserva las secuencias del habla, los movimientos del cuerpo de los participantes, la manipulación de instrumentos. Pero, de todas maneras, el uso del vídeo como fuente primaria de datos sigue constituyendo una suplantación o superposición sobre la realidad de las categorizaciones externas e indirectamente de la teoría sobre la realidad analizada (Goodwin, 1994). 2) A partir del vídeo y del audio se crea otra representación, esta vez de la transcripción verbal que puede introducir otros acontecimientos (Hutchins y Klausen, 1996). 3) Con las transcripciones descritas se genera una tercera representación de los hechos grabados, dado que el flujo del comportamiento en la transcripción se segmenta en partes o trozos significativos, aunque relacionados a partir de un sistema etnográficamente basado en objetivos y expectaciones de las acciones significativas para los participantes. Se intenta aquí ser muy explícito sobre los fundamentos de la composición y descomposición de cada acción. 4) Una cuarta representación de los acontecimientos consiste en la interpretación de las acciones que se han identificado anteriormente. Como cualquier acción particular identificada, esta nueva traslación, (interpretación) puede tener muchos significados, puesto que se ha de basar explícitamente en una etnografía lo más independiente posible y verificable de la situación. 5) Finalmente, a partir de todas estas representaciones, se trata de esbozar un mapa teórico. De esta forma, la teoría de la AS/CSD se va desplegando sobre la propagación de los diferentes estados de las representaciones intermedias. Cada representación aporta un nuevo tipo de información.

Las transcripciones de conversaciones como datos primarios suelen ser descripciones densas y extensas de situaciones institucionales y/o acciones en el flujo de su realización. Estas transcripciones de los lugares de trabajo o de la vida cotidiana no son fáciles, ya que los hechos y/o el habla en situación presentan aspectos contradictorios y numerosas voces argumentativas: la 
situación es para la AS/CSD un proceso de resolución negociada de problemas. Pero es importante la complementariedad de lo textual con las representaciones gráficas; éstas últimas tienen una función reflexiva que rompe el denso flujo de la escritura, forzando al escritor y al lector a parar, mirar y contrastar. A partir de aquí, la comparabilidad, la síntesis y el contraste analíticos van aclarando una posible cacofonía posiblemente sólo aparente. Todas estas transcripciones son sucesivas "visiones y lecturas» de lo observado, que tienen un efecto reductor e interpretativo de la realidad y que pueden dar a luz o el incremento de la teoría o nuestros intereses y prejuicios. Pero es necesario hacer estas traslaciones tratando de no dejar ningún supuesto en cuarentena.

\section{PARTE \\ INSUFICIENCIAS DE (Y APORTACIONES A) LA TEORÍA DE LA AS/CSD}

Vaya por delante mi aceptación básica con la perspectiva de la AS/CSD. Pero la crítica más evidenciable que, en mi opinión, se puede hacer de ella es la ausencia de una conceptualización social sólida de la acción o actividad, de la situación/contexto y de la misma interacción. De hecho, sus tratadistas no la explicitan o no le dan la importancia conveniente o, sencillamente, es inexistente. Esta perspetiva teórica, al no ser coherente y consistente, se reclama según los autores, tanto de la fenomenología sociológica o antropológica, del pragmatismo e interaccionismo, de la semiótica, como de la dialéctica marxista. Tanta variedad algo divergente parece sospechosa y excesiva. En mi opinión no se puede hablar de AS/CSD sin definir o dar contenidos coherentes a la idea de práctica/acción social, a la de situación y/o contexto y a la de interacción social. Y, desde luego, aunque algunos autores hayan pretendido basar su teoría de la AS/CSD en alguna versión de una dialéctica «dulce» o de la fenomenología psico-sociológica, sobre todo etnometodológica, no se puede asimilar a ninguna de ellas vista globalmente. Mi impresión es que la AS/CSD es por ahora un conjunto parcialmente cohesionado y pragmático de preocupaciones, un proceso de investigación y de resultados con bases metodológicas próximas a las de la etnografía y antropología culturales y que lo que más unifica a la AS/CSD es su oposición a todo lo que puede significar actividad o cognición simbólico-programada próxima a la IA clásicas. Para tratar de apuntalar algunos elementos que me parecen decisivos en la teoría de la AS/CSD, trato sin excesiva extensión, en primer lugar, una aproximación a la acción/actividad social en 1, segundo, la idea de contexto y situación social en 2 y, tercero, la de interacción social en 3. Estos conceptos me parecen claves en la identificación de la AS/CSD. 


\section{La acción y la actividad sociales}

El concepto de la acción social es uno de los objetos más centrales y a su vez controvertidos en la sociología, no en vano constituye su componente más primario. La polisemia y la sinonimia, ligadas a expresiones tales como prác tica, acción, praxis, interacción, acto, actividad y actuación no son inocuas teórica ni pragmáticamente. Por ello es de necesidad establecer alguna mínima distinción que sea pertinente a nuestro objetivo de considerar la acción, o actividad, primero como diferenciada de otros hechos o fenómenos sociales y, al mismo tiempo, situada e implicada cognitivamente. La idea de práctica la entenderé de manera genérica: con ella me refiero al conjunto de los contenidos como, por ejemplo, acción, actuación, producción, acontecimiento, praxis, acto o hecho, actividad, comportamiento. Consiste en todo lo que de común caracteriza a todos estos hechos o fenómenos sociales. La práctica es la relación que se establece entre una realidad observable, evidenciable o significante en tanto que medio, instrumento (soporte), recurso $\mathrm{u}$ orientación, y otra, no necesariamente observable, que es su objetivo, sentido o significado. Evidentemente, esta relación no está fijada ni predeterminada, por tanto posee algún grado de indeterminación. La razón es, entre otras, porque toda práctica 1) está llevada a cabo por sujetos sociales en parte libres con relación a los instrumentos, recursos o significantes que «aportan» a la práctica y también con respeto al sentido, objetivos o interpretación o significado de la práctica y 2) porque la práctica se realiza en contexto de interacción que comunica adicionalmente su propia orientación y sus propios contenidos siempre situacionales. La práctica además está atravesada por varias dimensiones, lo que la configura, identifica y especifica. ¿Qué se entiende por acción y/o práctica en la AS/CSD?, al menos no parece explicitarlo suficientemente.

Me interesan resaltar aquí algunos "tipos de prácticas» a partir de tres momentos del proceso de su desarrollo: momentos A, B y C. En realidad, se trata de distintos modos de manifestarse la práctica tomando como centro el proceso de interacción. El momento A o de la acción social: en él la práctica es la propia del sujeto social que la lleva a cabo en tanto que "previa» a su realización, pero en vistas a la interacción; es decir, se toma el sujeto social como centro de referencia a partir del cual y según su punto de vista se realiza la observación. En A la práctica tiene un componente instrumental observable pero está informada o recibe su sentido a partir de la intencionalidad (consciente o no, manifiesta o no), propósito, proyecto o motivo del sujeto; es decir, se tiene en cuenta un indudable contenido cognitivo. Pero instrumento e identidad de sentido se recrean mutuamente en la práctica. La práctica es entonces acción (social, en cuanto que lo es para una interacción). La relación entre su sentido y su parte evidenciable, objetivable o externalizable de la práctica no está dada necesariamente por una correlación preestablecida; es el sujeto quien la establece con el grado de aleatoridad propia a una situación previsible e imaginada como es la posible interacción. Esta defini- 
ción de la acción tiene un elemento indudablemente situacional, ya que es necesario para «fijar» la relación entre sus componentes. Tiene también un elemento cognitivo, dado el peso intencional atribuido al sentido u objetivo de la misma. El momento B, el de la interacción social: en el segundo momento, $\mathrm{B}$, la práctica social de un actor interfiere con las prácticas de otros actores como interacción social. El marco de referencia, centro de gravedad, unidad de análisis y puesto de observación de este momento ha cambiado ahora, ya que es la misma interacción. Por consiguiente, está des-centrada con relación a los sujetos intervinientes. Cada sujeto, agente o actor, aislado no puede ser el centro de la observación o del análisis. Es la interacción el único centro posible. En la interacción, la «participación» situacional se incrementa, pues se crea/recrea en (y crea) la interacción. Se incrementa también el componente cognitivo, puesto que en el proceso intervienen elementos representacionales, perceptivos, etc., sobre las intenciones y las representaciones propias de cada sujeto y sobre su medio o recursos. El momento $\mathrm{C}$, el del hecho o acto social: el flujo de la vida social surge en el suceder de interacciones y se establece en los hechos sociales que son el resultado de las interacciones y que, a su vez, son tomados como elementos significantes para nuevas interacciones. En el momento del hecho social la práctica (hecho o acto) cambia de nuevo de referencia y es contemplada como exterior al actor social y posterior a la acción e interacción; de alguna manera "fuera» de los sujetos sociales que la han desarrollado, aunque no esté desapropiada de ellos, bien al contrario. En el hecho social la práctica social se contempla como realizada, inserta y articulada en el contexto en la que ha surgido, pero como parte del mismo y apropiada por los actores, cognitiva o activamente, intervinientes; es considerada como acto o hecho social o actividad. El acto, hecho o actividad social constará también de su significante y de un significado, pero éste último podrá ser objetivado en función de su localización en la estructura del contexto y de la apropiación del mismo por los sujetos sociales. Podrá así ser leído por los propios sujetos sociales que han intervenido en la interacción o por otros observadores, incluyendo el investigador social. Esta lectura no puede hacerse sin el contexto en el que se inserta y se estructura por la apropiación/desapropiación por algunos o los actores.

Es importante retomar las definiciones dadas, sean de la acción, interacción o hecho, acto o actividad social, en el sentido de que contienen todas ellas dos componentes constituyentes: un elemento significante, más instrumental, de recursos, objetivable que da visibilidad y por tanto es perceptible y otro de significado, de sentido o intencional, de naturaleza más cognitiva, soporte de representaciones, interpretaciones, intencionalidad, categorizaciones, etc. Las definiciones de la acción y del hecho o actividad social no pueden desprenderse de ambos, pues en la relación está su identidad. Si miramos la acción, los elementos cognitivos se sitúan en los actores intervinientes, si en la interacción estos elementos están en las representaciones de los recursos y estrategias mutuos, si el acto, hecho o actividad social, están distribuidos, pues es un resultado apropiado. 
La idea de actividad, permanentemente usada aquí, parece que a veces pudiera asimilarse a la de acción, interacción o a la de acto o hecho social, según lo que se analice. Con todo, parece que se acerca más a la idea de acto o hecho social en el sentido dado aquí como recursos y resultados de la interacción distribuidos, sean cognitivos o de otro orden. Lo que es claro es que el estudio de la actividad social no puede dejar de lado ni sus componentes básicos, ni su procedencia que es la acción, ni el meollo del proceso que es la interacción, ni su estructuración cristalizada que es el hecho. Estas distinciones no aparecen en la visión que dan sus propios autores de la AS/CSD. Sin embargo, en ellas se encuentran en germen todos los elementos con que he ido describiendo precedentemente la identidad de la AS y/o CSD.

\section{La actividad situada, situación, contexto y el control/poder}

¿Dónde comienza y acaba una acción? ¿Dónde lo hace el hecho, acto o actividad social? He aquí una pregunta de difícil solución donde las haya en sociología y que no parece se la hagan los investigadores en AS/CSD. En principio, la acción social ha de tener su límite allí donde termina el proceso intencional, manifiesto o latente, consciente o no, del sujeto que configura la acción. Puede llegar a ser muy extensa, por ejemplo, la vida entera si se considera como una acción informada por lo que se denomina el «horizonte temporal como sentido». Para Schütz solamente el actor sabe lo que hace, por qué lo hace y dónde acaba y comienza la acción. Estoy de acuerdo, pero a veces no lo sabe o solamente lo intuye o, si lo sabe, o no lo explicita o no sabe hacerlo y por tanto no tiene entendimiento y/o conciencia de los límites de su acción. Pero es verdad que es el sujeto el soporte de la intencionalidad de su acción y, por tanto, quien interrumpe su continuidad. La acción termina donde se consume o frustra su propósito y perdura mientras dure la interacción que pretende llenar su intención. Es por tanto el sentido intencional lo que marca el límite de la acción. Pero toda acción aboca a la interacción y por tanto es en ella donde alcanza su contenido intencional. Como interacción crea y se recrea en la situación, y será en la situación donde se cierra o se consume la acción. La situación es la unidad de análisis en que se contextualiza y se define la acción en forma de interacción y donde se ponen en funcionamiento, hasta su consumación, los proyectos de los sujetos que participan. Por tanto, la acción no es ilimitadamente dilatable o prolongable, como tampoco lo es la situación. Otra cosa es que una situación sea parte de otra situación, etc. El problema se traslada entonces a la definición o límite de la situación de interacción.

Los límites de la interacción están marcados por los sujetos en interacción y por las aportaciones que a ella llevan, junto con sus proyectos y estrategias. Es complicado establecer sus límites porque las identidades sociales de los intervinientes en la situación pueden venir de lejos, ya que sus recursos se ramifican (pensemos en las redes sociales), porque los rescoldos cognitivos de su resolución se guardan en el tiempo, etc.; hasta las delimitaciones más evi- 
dentes como las espaciales y temporales son elásticas. Con todo, desde el punto de vista pragmático y operativo, se puede llegar a buenas aproximaciones de la clausura de las situaciones. Los límites de la situación están fundamentalmente marcados operativamente por lo que llamo soportes o substratos de la misma, que son básicamente materialidades como el espacio, el tiempo, las relaciones, los objetos o artefactos que manipulan o convergen en la interacción, la energía y la información. Estas realidades que marcan primeramente los límites de la situación son de la incumbencia de los sujetos, es decir, como producto, apropiación y recurso de los sujetos intervinientes, pero siempre identificables en sus fronteras. Lo que da paso a otra situación es pues fundamentalmente el cambio en la entidad de los sujetos intervinientes con el conjunto de elementos que los definen. Pero, incluso así, los marcadores como el espacio físico, el tiempo, los objetos o artefactos y la información son buenos indicadores de fronteras situacionales que acompañan a la dada por los cambios de los sujetos presentes en la interacción. Al cambio de los marcadores, tiempo, etc. puede corresponder un cambio de la situación, ya que suele conllevar un cambio en el sujeto social aunque no esté de «cuerpo presente» en la situación. Éste es pues el criterio básico de su frontera y que exige (o es consecuencia de) la continuidad y unidad de los actores y del relativo mantenimiento de los elementos precedentes. Así pues, la situación perdura mientras no se rompa la identidad y presencia de los actores en actuación en una cierta unidad espaciotemporal y hasta que no se llegue a un resultado identificable, apropiable y apropiado. Los factores, pues, que establecen límites o fronteras a las situaciones se aproximan a los clásicos «quiénes, qué, cuándo, cómo, dónde y por qué». Esto es importante a la hora de establecer la unidad de análisis básica en los estudios de AS/CSD.

El acto, hecho o actividad social es, diferentemente a la acción, el abocamiento de una acción en situación de interacción como resultado. En este sentido el acto o actividad, en su parte significante, es un hecho observable $y$, en cuanto a significado, es un sentido objetivado que puede ser descubierto a partir de su articulación en la situación o situaciones, contextos, con la(s) que se engarza. En el acto, como resultado de la interacción, es donde se reestructura la situación por la reapropiación de la misma; por tanto, es donde se redistribuye socialmente, por ejemplo, entre otras cosas, el conocimiento. Además, el significado del acto o hecho social proviene de otras incidencias e instancias que las únicamente marcadas por el sujeto que no son aún, menos que la acción y la interacción, controlables absolutamente por él. Es el resultado del juego interaccional y por tanto de las diversas acciones intervinientes. De alguna manera el hecho se «independiza» de las acciones y no está ya, por consiguiente, informado por procesos intencionales más que en la medida que han contribuido a su realización o que pudieran ser retomados para nuevas (inter)acciones, por ejemplo, con fines de investigación. Es importante, por consiguiente, establecer desde el principio esta distinción, creo que ontológica y no meramente nominal y/o analítica, entre, por un lado, el sentido o la intencionalidad del sujeto en la acción social (pieza impres- 
cindible para definirla) y el significado objetivable del acto social que se deriva de la red de vinculaciones que se dan en la estructura situacional en la que se inserta o se modifica el acto social ${ }^{14}$.

Antes de que surja cualquier forma de autoconciencia, el sujeto social se encuentra en situación a través de las condiciones materiales, sociales y culturales en las que comienza su existencia. Esta implicación o pertenencia original del sujeto a una situación se realiza física y simbólicamente por y en numerosas prácticas, entre las cuales el lenguaje, la manipulaciones y los usos de la realidad, el contagio del hábito, las representaciones sociales y las diferentes técnicas de manipulación y uso de las cosas, etc. son decisivos.

El punto de vista que sostengo es que no puede hablarse del contexto y/o de la situación de manera fría, cual cariátide que contempla o se contempla en la interacción con una función meramente decorativa para una interpretación de la (inter)acción. No se dan, por un lado, los actores que realizan la interacción y, por otro, un contexto en el que aquéllos se «inmerjan». Todos los elementos de la situación intervienen en la interacción: o son parte y apropiación, "prolongación» en recurso o instrumento, de los actores "aquí-y-ahora», o de otros no visibles pero que actúan en ella, aliados/coaligados con algunos de los presentes o en franca concurrencia. En sentido estricto cuando, por ejemplo, se manipula un artefacto, la interacción se está produciendo «delegadamente» con el diseñador/productor/empresario que lo compusieron y con la institución que se lo apropió y lo puso a disposición del agente que lo maneja. Esto es importante a la hora de hablar de manipulación social de los artefactos, pues de lo contrario es imposible entender que se pueda dar una interacción cognitiva y/o social en tal manipulación y que el agente pueda modificarse por ella y en ella. Solamente se interacciona entre sujetos sociales, no se interacciona con las máquinas, que no presentan ni recursos propios, ni estructuras de sentido ni proyectos intencionales. No está mal recordarlo a los promotores y prominentes de la AS y/o CSD, aunque, supongo, que lo dan por supuesto ${ }^{15}$.

14. Como se ve, la acepción dada aquí a la acción, interacción, hecho y situación sociales trata de evitar las fuertes antinomias dadas en tradición sociológica, en las que no entro por ahora. Esta acepción no puede aparentarse exclusivamente a la de la fenomenología, ni a la del pragmatismo, ni a la de la dialéctica, ni desde luego a la de un neopositivismo tout court.

15. La situación y el contexto no es un marco decorativo de la interacción que pueda intervenir más o menos en el desarrollo de la misma; sus componentes lo son de la interacción. Desde mi perspectiva, nada hay en la situación que sea ajeno al conjunto de sujetos sociales que intervienen "de cuerpo presente o ausente», por tanto, el problema no consiste en ver «cómo las acciones derivan de las situaciones» o en qué medida están determinadas socialmente, ya que todo está en la situación percibido, apropiado y reutilizado por los sujetos sociales. Las paredes, los tiempos, los lugares, las estrategias, los recursos, etc., tienen pertinencias/pertenencias o identidades sociales, pues son producto de anteriores interacciones o intervienen en las siguientes. En mi perspectiva nada es ajeno a lo social, ni la farola que cansinamente desvanece las sombras en el anochecer de una plaza pública, ni el resurgir del sol que la calienta al relente del amanecer. La ecología social no es un barniz ambiental: es parte viva del fenómeno social. 
De lo dicho se deduce que hay otro aspecto crucial en la interacción/situación; es el poder, o lo que llamaré más bien «la capacidad y la realidad de la apropiación, dominación o control de la estructura de la interacción por los sujetos sociales». El poder aparece como una dimensión directamente orientada para tratar, negociar, doblegar o domesticar los productos de la interacción. Este aspecto no tiene ninguna relevancia en algunos de los promotores de la teoría de la AS/CSD, posiblemente porque sus orígenes disciplinarios no se lo exijan tanto, ya que suelen ser especialistas de lo cognitivo, etnógrafos, psicólogos, antropólogos, y en general de lo micro. Nada hay en la interacción que no esté y/o haya de ser apropiado por los actores intervinientes en ella, presentes o no. Por tanto, escenarios, trastiendas, decorados, otros actores, evidentemente los estatus, roles, posiciones en la estructura, bienes, dinero, información, ideología, etc., es decir, todos los elementos de las estructuras sociales que «rodean» y son parte de los sujetos y de la acción son parte de la situación.

\section{La interacción social}

La interacción es la piedra de toque, fogón y dinámica por la que las acciones pasan a hecho o acto o actividad sociales, es decir, se distribuye socialmente por las correspondientes apropiaciones de sus resultados. En la perspectiva aquí adoptada la interacción es la puesta en juego por los sujetos sociales en presencia de diversas estrategias o acciones, sean de solidaridad o de intercambio, para la consecución o consolidación de la apropiación de diferentes bienes, recursos, beneficios, etc. Dicho control o apropiación establece y estructura el hecho social. Hay dos estrategias básicas de interacción, la de solidaridad y la de intercambio. Las primeras se refieren a las relaciones que tienden a consolidar o asegurar el Nosotros (Yo) cara a los Otros (Tú) y, las segundas, a las relaciones del Nosotros con los Otros (el Yo y el Tú como parte del Nosotros en perspectiva social). Ha de quedar claro que la interacción es el elemento dinámico o "semilla» del hecho social y la situación, su humus o caldo de cultivo. Parece que los autores de la AS/CSD priorizan la estrategia de colaboración dejando de lado la conflictiva, lo que no deja de ser un sesgo importante en su teoría. La interacción social es una noción básica en sociología, lo es también en psicología, en particular en psicología social, en antropología cultural y social, en la pragmática lingüística y en general en el análisis del discurso y en la etnografía. Debería de serlo también en cualquier tipo de teorización de la AS/CSD.

Teniendo en cuenta los diversos elementos que intervienen en la interacción, su dinámica y la posibilidad de su estructuración, consideraré la interacción como un intercambio y concurrencia real de varios sujetos sociales/proyectos en presencia (no necesariamente de "cuerpo presente») y con estrategias orientadas a la apropiación (y/o coapropiación) de los bienes, recursos o valores de los otros sujetos. La interacción se realiza en unos campos o valores sociales (de uso, económicos, cognitivos), que le transfieren 
su especificidad o identidad. El estado social resultante puede ser de equilibrio estable o inestable. La dinámica (o motivación) de la interacción proviene del proyecto o estrategia por la apropiación o usufructo de un bien apetecible producido en la interacción.

En la interacción intervienen diversos elementos. 1) El proyecto/actor es la relación que el sujeto establece entre dos componentes, de un lado, la parte de los recursos (estructuras contextuales de pertenencia o inserción) que el sujeto aporta a la interacción, de otro, el sentido o contenido intencional a conseguir en la previsible interacción. Los recursos (sean la pertenencia a una clase social, la posición social, la ideología y sus medios correspondientes; sean su inclusión en una organización, empresa, profesión, entorno cercano espacial y temporal, objetos, etc.) se actualizan para la situación por mecanismos inherentes a los hábitos cognitivos (percepción, memoria, representación e intención), hábitos éticos y de control (o apropiación). La intención consiste en la anticipación y retroacción al presente de una previsible situación futura de apropiación cognitiva, ética y control de los beneficios posibles y obtenibles a partir del resultado de la interacción. El proyecto es equivalente a la estrategia en el sentido que vincula medios, que son los significantes o recursos de la acción de interacción, con la intención de apropiación. 2) La dinámica de la interacción consiste en la acción de concurrencia entre los proyectos de los sujetos sociales en vistas a la apropiación del resultado de la interacción. 3) El punto de llegada en una nueva identidad como resultado de la (inter)acción.

La interacción está pues estructurada, es decir, tiene una composición y presenta regularidades observables. Su estructura consiste en la forma de combinar o relacionarse los diferentes recursos, proyectos o estrategias, medios y objetivos de los participantes en la situación, es decir, las formas de jugar el juego ${ }^{16}$. Desde mi punto de vista, esta estructura tiene una entidad ontológica. Es fundamental esta aseveración, pues es la única manera de evitar cualquier forma de reduccionismo o de disolución de la interacción o en los procesos intencionales o en lo que he llamado «estructuras contextuales propias del hecho social». Por ello es necesario aceptar, 1) la diferencia ontológica entre la estructura de la interacción y la estructura contextual y 2) una conceptualización y metodología que articule la interacción con sus condiciones contextuales, para que no se caiga ni en una teoría mecanicista de la acción, ni en el terreno de un ingenuo y único cambio de intersubjetivida-

16. En Goffman la estructura de la interacción permite reducir la impredicibilidad del comportamiento, p. e. 1) al mantener las apariencias de normalidad evitando la ambigüedad; 2) al controlar la intimidad y la accesibilidad, 3) al dar indicaciones sobre la estructura de las ocasiones sociales, es decir, lo que Goffman denomina la organización de la reunión o concurrencia; 4) al mantener las relaciones positivas; y 4) al presentar la propia identidad, lo que supone el control de la información disponible a otros para dar la impresión adecuada para exigir o reclamar un rol particular durante la interacción. 
des. Muchas posiciones sociologizantes son incapaces de aceptar esta doble ontología y su relación, por lo que el monismo reduccionista es un plato habitual en sociología y otros sociologistas más o menos constructivistas ${ }^{17}$. Los elementos de la estructura de la interacción contienen los recursos puestos en juego: elementos intencionales (propósito, motivación), capacidades cognitivas como representaciones y otras en la definición de la situación y la capacidad negociadora ${ }^{18}$.

Si la interacción tiene una estructura y además es dinámica, como supongo, poseerá también la capacidad de desarrollar sus propios rasgos en situaciones específicas que, de todas formas, sabemos que dependen también de rasgos contextuales. Esto es posible porque en el proceso de la interacción los sujetos sociales son capaces de interpretar, apropiarse y desear apropiarse de significados, reglas, definiciones y, en general, de recursos, etc., que permiten constituir y prolongar la interacción; es decir, hay una dinámica interactiva. La dinámica de la interacción "arranca» del intento de apropiación de los estados o recursos de los intervinientes según y a partir de sus proyectos recíprocos. Los diferentes recursos y/o soportes son simultáneamente mecanismos o instrumentos de interacción y, al mismo tiempo, el contenido intencional o proyecto de apropiación y apetencia de los sujetos concurrentes. Los hábitos son instancias de mediación y también recursos que intervienen en las formas de cognición, adecuación y apropiación de los recursos. Tomando el símil conversacional, se puede adoptar una imagen de la dinámica de la interacción como interlocución entre proyectos en presencia que

17. Los etnometodólogos resuelven la contradicción que se presenta entre, de un lado, la explicación de la interacción social en términos de las condiciones externas que la determinan y, de otro, la explicación a partir de los actores participantes como activos y autónomos y no como autómatas deshumanizados, prescindiendo de las constricciones de las condiciones estructurales y favoreciendo un cierto determinismo situacional.

18. Esquema de la estructura de la interacción a partir de sus elementos intervinientes.

Sujeto A

Proyecto de A: Articulación de:

A1. Parte significante del proyecto de A (estructura significante del royecto), que a su vez es articulación de:

A1.1. Recursos materiales: espacio, tiempo, objetos, energía, información.

A1.2. Recursos de legitimación: normas, ideología, lenguaje, prestigio.

A2. Estructura de sentido del proyecto de A, que su vez es articulación de:

A2.1. Actualización de experiencias vividas de posesión satisfactoria de bienes o recursos.

A2.2. Intención de apropiación satisfactoria de un bien u objeto poseido por otros sujetos sociales.
Sujeto B

Proyecto de B: Articulación de:

B1. Parte significante del proyecto de B (estructura significante del proyecto) que a su vez es articulación de:

B1.1. Ídem de A.

B1.2. Ídem de A.

B2. Estructura de sentido del proyecto de B que a su vez es articulación de:

B2.1. Ídem de A.

B2.2. Ídem de A. 
tienden a su mutua apropiación. En este caso se han de tener en cuenta, como en toda pragmática conversacional, todos los elementos que intervienen en la situación. Concibo pues la interacción como una relación entre las estructuras comunicativas de los sujetos sociales ${ }^{19}$.

\section{Observaciones finales}

Los objetivos de este artículo son diversos aunque coherentes en su desarrollo. He tratado de identificar y describir, muy pegado a sus promotores, lo que se denomina "actividad situada/conocimiento socialmente distribuido». Para ello he ofrecido una síntesis de sus componentes más definitorios, sus bases teóricas y metodológicas y algunas orientaciones de tipo técnico y de diseño de investigación, a fin de animar y guiar la práctica investigadora en dicha dirección. He resaltado una cierta carencia y/o ambigüedad o ambivalencia teórica, en el sentido de que sus autores lo mismo pueden reclamarse de la dialéctica olvidando a Marx que de la etnometodología dejando de lado a Schütz. Los elementos teóricos que manejan, al menos visto desde la sociología, aparecen como incursiones puntuales para etiquetarse de alguna corriente importante, pero sin que se explicite o desarrolle el nexo entre las teorías evocadas y su implicación en las investigaciones que muestran. Posiblemente, tal y como lo insinúo al principio, se trata de un conjunto de investigaciones y preocupaciones en busca de su teoría. De hecho, y es posiblemente una de las causas de mi esbozada crítica, pero también la razón de la fecundidad y pertinencia de esta perspectiva, las investigaciones que llevan esta orientación nacen de problemáticas, preocupaciones y preguntas reales e importantes: las que provienen de la búsqueda de respuestas interdisciplinares y originales a los interrogantes que plantean la relación de los actores con los nuevos artefactos «inteligentes», la interacción entre los mismos actores y la implicación de los contextos en la realización de la actividad de agentes y artefactos. He llamado la atención también sobre la profunda controversia que esta perspectiva mantiene con los valedores de la inteligencia artificial simbólica, siendo éste uno de los mayores acicates de su desarrollo. He hecho hincapié en su debilidad para abarcar contextos sociales más amplios que los, a

19. ¿Cómo se produce entonces la dinámica interactiva? Para que se dé la interacción se ha de producir, a partir del esquema precedente, un juego cruzado de comunicación apropiativa de la manera siguiente: el sujeto $\mathrm{A}$ ha de tener como estructura de sentido (A. 2), $\mathrm{o}$ intención de su proyecto, el apropiarse de (para hacerlo equivalente a) la parte significante del proyecto de B, (B.1) y el sujeto B ha de tener como estructura de sentido (B.2) $\mathrm{o}$ intención de su proyecto la de apropiarse de (para hacerla equivalente a) la parte significante del proyecto de A, (A.1). Éste es el "cruce mágico» y dinámico de la interacción: un juego de apropiaciones invertidas de los sujetos. Es la manera de respetar la naturaleza ontológicamente diferenciada de la estructura de significación (contextuales), los espacios o ámbitos intencionales y la estructura de la interacción, haciendo posible que su análisis no se reduzca ni a las constricciones asociadas a la estructura social contextual ni tampoco al de las intersubjetividades. 
veces, muy pegados a situaciones localistas y su despreocupación o desconsideración por poner en juego actores sociales más determinantes y de mayor envergadura que los directamente ligados a los aspectos más elementales y micros. Salvo en Cicourel, esta preocupación no suele estar presente y, sin embargo, es decisiva. Posiblemente esté explicado por el origen más bien antropológico, cognitivo y cultural de la mayor parte de sus promotores. Por fin, he tratado de precisar y desarrollar algunos de los aspectos que me parecen más desfallecidos en el armazón conceptual y teórico de esta perspectiva. Son precisamente los conceptos de acción, situación, interacción y hechos sociales los que me parecen más flojos de su arquitectura, conceptos más trabajados precisamente en sociología y en psicología social. Por ello, y como contribución, me he detenido al final algo en ellos.

\section{Bibliografía}

Agree, P.E. (1993). «The Symbolic Worldview: reply to Vera and Simon». Cogniti ve Science, 17, 61-69.

Agree, P.E.; Shrager J. (1991). Routine Evolution and the Culture of Speed.

BaKHTIN, M. (1981). The Dialogic Imagination: Four Essays. Austin: University of Texas Press.

Cicourel, A. (1994). «El conocimiento distribuido en el diagnóstico medical». Sociologie du Travail, 4: 427-449.

ClANCEY, W.J. (1993). «Acción situada: una interpretacion neurosicológica. Respuesta a Vera y Simon». Cognitive Science 1993, 17: 87-116.

Conein, B.; Jacopin, E. (1994). «Action Située et cognition, le savoir en place». Sociologie du Travail, 4: 475-500.

D'ANDRADE, R. (1989). "Culturally based reasoning». En GELlatly, A.; Rogers, D.; Sloboda, J.A. (ed.). Cognition and Social Worlds. Oxford: Oxford University Press, p. 132-143.

EngestrÖM, Y.; MidDleTON, D. (1996). «Introduction: Studding work as mindful practice». En EngeStröM, Y.; Middleton, D. (1966). Cognition and commu nication at work. Cambridge: Cambridge University Press, p. 1-14.

GOODWIN, C.; HARNESS GOODWIN, M. (1996). «Seeing as a situated activity: Formulating planes». En ENGESTRÖM, Y.; MidDlETON; D. (ed.) (1996). Cognition and Communication at Work. Cambridge: Cambridge University Press, p. 61-95. Goodwin, G. (1994). «Professional vision». American Anthropologist, 96 (3): 606633.

Greno, J.G.; Moore, J.L. (1993). «Situativity and Symbols: Response to Vera and Simon». Cognitive Science, 17: 49-59.

Grudin, J. (1989). "The Case against user interface consistency». MCC Technical Report Number.

Heath, C.; LufF, P. (1994). «Actividad distribuida y organización de la interacción». Sociologie du Travail, 4: 523-545.

HuTCHINS, E.; KLAUSEN, T. (1996). «Distributed cognition in an airplane cockpit». En Engeström, Y.; Middleton, D. Cognition and communication at work. Cambridge: Cambridge University Press, p. 15-33. 
Hutchins, E. (1981). «Reasoning in Trobriand Discourse». En Casson, R. (ed.) (1981). Language Culture and Cognition. Macmillan Publishing Company, p. 481-489.

- (1995). «How a Cockpit Temembers its Speeds». Cognitive Science 1995, 19: 265-288.

LaVe, J. (1988). Cognition in Practice: Mind, Mathematics and Culture in Everyday Live. Cambridge: Cambridge University Press.

LaYder, D. (1993). New Strategies in Social Research. Cambridge. MA: Polity Press.

LEIGH STAR, S. (1996). «Working together: Symbolic interactionism, activity theory, and information systems». En ENGeSTRÖM, Y.; Middleton, D. (1996). Cogni tion and Communication at Work. Cambridge. Cambridge University Press, p. 296-318.

LOZARES, C. (próxima aparición, 2000). «La actividad situada y/o el conocimiento socialmente distribuido en el estudio de un puesto de trabajo». Revista de l'Asso ciació Catalana de Sociologia.

LOZARES, C.; MARTín, A.; LOPEZ, P. (1998). «El tratamiento multiestratégico en la investigación sociológica». Papers. Revista de Sociologia, 55: 27-43.

Norman, D.A. (1993). "Cognition in the Head and in the World: An Introduction to the Special Issue on Situated Action». Cognitive Science 1993, 17: 1-6.

RAEITHEL, A. (1996). "On the ethnography of cooperative work». En ENGESTRÖM, Y.; Middleton, D. (1996). Cognition and Communication at Work. Cambridge: Cambridge University Press, p. 319-339.

STRAUSS (1993). Continual Permutation of Action.

Suchman, L. (1993). «Respuesta a la acción situada de Vera y Simon: una intepretacion simbólica». Cognitive Science, 17: 71-75.

Vellard (1994). «Pragmática cognitiva: de la aritmética de lo cotidiano a la inteligencia artificial». Sociologie du Travail, 4: 501-522.

VerA, A.H.; Simon, H.A. (1993). «Situated Action: A Symbolic Interpretation». Cog nitive Science, 1993, 17.

Vygotsky, J.V. (1978). Mind in Society: The Development of Higher Psychological Pro cesses. Cambridge, MA: Harvard University Press. 